\title{
The symbol linked explicit unpacking (SLEU) method for solving STEM problems
}

\author{
Adassa Phillips, Muizz Hassanali, James A. Wingrave, PhD, \\ Department of Chemistry and Biochemistry, University of Delaware, Newark, DE, 19716, USA \\ For correspondence: wingrave@udel.edu
}

\begin{abstract}
:
Solving STEM problems requires that data (numbers and units) from a word problem be substituted into a mathematical equation(s) for solution. However, solving STEM problems is an implicit process that provides little or no guidance for the problem solving process. In this study symbols linking the data to the mathematical equation(s) are used to develop an explicit unpacking method for solving STEM problems. This problem solving procedure is termed the SLEU (Symbol Linked Explicit Unpacking) method. The SLEU method provides an explicit stepwise framework to guide students in the solution of STEM problems from the word-problem format of most STEM problems to the mathematical set up and ultimate solution of the problem. Simultaneously, the SLEU method requires students to understand the physicochemical significance of the data in the word problem as it is used in the mathematical equation. The SLEU problem steps can be easily uploaded into software programs for distribution to students for individual, self-guided study.
\end{abstract}

Kewords: Explicit Unpacking, Symbol Linked Explicit Unpacking, Solving STEM Problems, Symbol Linked Explicit Unpacking Modules

\section{Introduction}

Improvements in a student's mathematical thinking skills have been shown in multiple studies to depend on the learners' prior mathematical knowledge (Shulman \& Keislar, 1966; Bauersfeld, 1995; Lesh \& Doerr, 2003). Other studies have explored the manifestation of this connection using mathematical problem solving ability (Schoenfeld, 1992; Lester, 1994). A somewhat surprising result of these studies is that prior mathematical knowledge can also be a constraint to solving mathematical problems. This constraint is found to result from the learners' inability to transfer the prior knowledge when confronted with a new application (Niss, Blum \& Galbraith, 2007). Investigations into this latter tenant is the subject of ongoing research elsewhere (Adams, 2012; Zhang, Manouchehri \& Tague, 2013).

While these studies have explored the causes for mathematical problem solving success or failure, none provide an explicit problem solving method for the learner to use. The current paper will focus on developing an explicit format based on the method of unpacking for finding mathematical solutions to STEM problems. The role of cognition and metacognition in this process will also be discussed.

Unpacking is one of the more widely recognized methods for solving complicated STEM problems. Doll (1989) describes the unpacking method as how, "students picked apart problems and reconstructed them into new problems". In 1994 Caine et al., describe the goal of unpacking as, "unpacking of fundamental concepts to seek deeper meaning". Ball \& Bass (2000) describe the method, "as unpacking the content" and then the implementation of unpacking as, "a decompression or deconstruction of basic mathematical concepts and skills in order to reexamine and reconstruct with understanding." 
While these statements implicitly describe and define what unpacking is, they do not provide an explicit method for using unpacking to solve problems. These descriptors for unpacking may be satisfactory for the expert learner but are not of much help to the novice learner. Moreover, these descriptions may describe unpacking but they do not describe how to apply the unpacking process.

A STEM problem is a word problem with data, i.e., numbers and units, but usually no symbols. A successful STEM problem solution requires solving a mathematical equation containing symbols but no data. The obvious connection between a STEM problem with data and the mathematical equation(s) is the symbols. More specifically, a STEM problem solution requires that data be associated with symbols so that symbols in the math equation can be replaced with data. Symbols are the link between data and mathematical equations in solving STEM problems. Equating symbols to data serves to produce a physicochemical understanding of the data and symbols in the mathematical equation.

A STEM problem solution requires finding data values for symbols in a mathematical equation so that the equation can be solved for the desired equation variable. The method described in this paper combines all of these steps into a single problem solving method. This method derives its name from linking the data (numbers and units) in a STEM word problem with a symbol that appears in a math equation. This method of solving STEM problems is termed, Symbol Linked Explicit Unpacking or SLEU. In the SLEU method the symbols are the link between the data in the word problem and the symbols in the mathematical equation.

The SLEU method is an unpacking process that provides a framework for students to use to organize the explicit unpacking steps in STEM problem solution in order to arrive at a quantitative mathematical answer. This paper will explore how the SLEU method can be used for solving STEM problems. It will also describe how to write an SLEU solution in order to upload the SLEU-solved problem into a PowerPoint ${ }^{\mathrm{TM}}$ format for self-study by students. Examples of SLEU Modules are provided.

\section{Discussion}

The principle difficulty students have with solving STEM problems lies in the multiple, complicated steps required for a solution. In overview, a STEM problem starts as a word problem that must be explicitly unpacked to give a math solution. The process of unpacking STEM problems is a multiple step method that also involves mathematics and physicochemical principles. Moreover, the unpacking steps must be performed in a precise order without omitting or reversing any of the steps. This process is made difficult because most STEM problems;
a) start as word problems,
b) require math solutions,
c) require multiple types of steps for solution,
d) have steps based on physicochemical principles,
e) require the steps to be performed in precise order,
f) etc.

For the expert learner, i.e., the instructor, the solution is achieved by recalling and organizing the necessary steps from long term memory. For the novice learner, i.e., the student, these steps may or may not exist in their long term memories. Moreover, even if all the steps do exist in long term memory of the novice learner, the knowledge for correctly organizing these steps to achieve a solution commonly does not exist. This results in student comments like, "I couldn't work the test problems even though I, 1) knew the material, 2) knew all the equations, 3) understood the lectures, 4) did all the homework problems, 5) came to office hours, 6) hired a tutor, 7) ..." 
The SLEU method has three simple steps given in Figure 1.

\begin{tabular}{|c|l|}
\hline Step & \multicolumn{1}{|c|}{ DESCRIPTION } \\
\hline & \\
\hline I & UNPACKING (NUMBERS, UNITS) \\
\hline 1a & Extract numbers and units from the word problem \\
\hline & \\
\hline II & UNPACKING (SYMBOLS WITH SUBSCRIPTS) \\
\hline 2a & Assign symbols and subscripts to numbers/units including symbol being sought. \\
\hline III & EQUATIONS AND SOLUTION \\
\hline $3 \mathrm{a}$ & Find Equations for Symbols and substitute numbers and units \\
\hline $3 \mathrm{~b}$ & Solve equations \\
\hline & \\
\hline & REFERENCES: PRACTICE PROBLEMS AND READING \\
\hline & \\
\hline
\end{tabular}

Figure 1. Solving STEM problems by the SLEU method

In applying the SLEU method, it should be noted that some STEM problems are so simple that an SLEU solution might not be needed. Of course this depends not only on the complexity of the STEM problem but also on the education level of the students for which it was written. For example, PROBLEM A, is an example of how a simple STEM problem would be solved using previous knowledge driven by intuition and not requiring symbol linked explicit unpacking.

PROBLEM A: What is the volume In cubic feet of a room that is 12.6 feet long, 8.00 feet 9.0 inches wide and 8.00 feet high.

Unpacking Problem A involves plugging data from the word problem into a familiar mensuration equation, the volume of a right rectangular prism, i.e., a room. Solving the equation for the volume yields the final answer. The advanced student intuitively writes down the equation for volume, plugs in the length values and solves for the room volume. The advanced student calculates the answer to the problem unaware of the unpacking steps they used in arriving at the solution. Conversely, an SLEU solution for Problem A might be advisable for a novice student.

An SLEU solution for Problem A can be written as follows.

I) UNPACKING (NUMBERS AND UNITS):

$$
12.6 \mathrm{ft} \quad \vdots \quad 8.00 \mathrm{ft} 9.0 \mathrm{in}=8.75 \mathrm{ft} \quad \vdots \quad 8.00 \mathrm{ft}
$$

\section{II) UNPACKING (SYMBOLS WITH SUBSCRIPTS):}

$\mathrm{V}\left(\mathrm{ft}^{3}\right)=? ? \quad \vdots \quad \ell=12.6 \mathrm{ft} \quad \vdots \quad \mathrm{w}=8.00 \mathrm{ft} 9.0 \mathrm{in}=8.75 \mathrm{ft} \quad \vdots \quad \mathrm{h}=8.00 \mathrm{ft}$

\section{III, 3a) EQUATIONS AND SOLUTION: Find equations}




$$
\mathrm{V}=\ell \mathrm{w} \mathrm{h}
$$

\section{III, 3b) EQUATIONS AND SOLUTION Solve problem:}

$$
V=\ell w h=(12.6 \mathrm{ft})(8.75 \mathrm{ft})(8.00 \mathrm{ft})=\underline{\underline{882 . \mathrm{ft}^{3}}}
$$

When STEM problems get more complicated, the instructor must decide whether students will benefit from practice with the SLEU method or just solve problems intuitively as was done in Problem A, above. For more complicated STEM problems, intuitive solutions, such as for Problem A, will fail. Specifically, the unpacking steps become more numerous and complicated and must be divided and organized into explicit steps, i.e., SLEU. As an example consider the solution to a more complicated STEM problem, PROBLEM B.

PROBLEM B: At 2:00pm a northbound train passes through the Newark, DE train station traveling at $55.0 \mathrm{mph}$. At 2:00 pm a southbound train passes through the Philadelphia, PA train station traveling at $75.0 \mathrm{mph}$. If the train stations are 45.0 miles apart, where will the trains pass each other? (Be sure trains are on separate parallel train tracks! $\odot$ )

If we start by looking at the solution of this problem as it might appear in a solutions manual it might appear as Figure 2.

$$
\begin{aligned}
& \overbrace{X}^{\text {Newark }} \underbrace{\stackrel{\ell_{N}}{\longrightarrow}}_{55 \mathrm{mph}} \mid \underbrace{\underbrace{\ell_{P}}_{\mathrm{P}}}_{75 \mathrm{mph}} \overbrace{\mathrm{X}}^{\text {Phil }} \\
& \mathrm{v}_{\mathrm{N}}=55.0 \frac{\mathrm{mi}}{\mathrm{hr}}=\frac{\ell_{\mathrm{N}}}{\mathrm{t}} \quad \vdots \quad \mathrm{v}_{\mathrm{P}}=75.0-=\frac{\ell_{\mathrm{P}}}{\mathrm{t}} \quad \vdots \quad \ell_{\mathrm{T}}=\ell_{\mathrm{N}}+\ell_{\mathrm{P}}=45.0 \mathrm{mi} \\
& Q \text { : What is constant when the trains meet? A: time } \\
& \mathrm{t}=\frac{\ell_{\mathrm{P}}}{75.0 \frac{\mathrm{mi}}{\mathrm{hr}}}=\frac{\left(45.0 \mathrm{mi}-\ell_{\mathrm{N}}\right)}{75.0 \frac{\mathrm{mi}}{\mathrm{hr}}}=\frac{\ell_{\mathrm{N}}}{55.0 \frac{\mathrm{mi}}{\mathrm{hr}}} \vdots 55.0 \frac{\mathrm{mi}}{\mathrm{hr}}\left(45.0 \mathrm{mi}-\ell_{\mathrm{N}}\right)=75.0 \frac{\mathrm{mi}}{\mathrm{hr}} \ell_{\mathrm{N}} \\
& 2,475 . \mathrm{mi}-55.0 \ell_{\mathrm{N}}=75.0 \ell_{\mathrm{N}} \quad \vdots \quad 2,475 . \mathrm{mi}=130.0 \ell_{\mathrm{N}} \\
& \ell_{\mathrm{N}}=\frac{2,475 . \mathrm{mi}}{130.0}=19.0 \mathrm{mi} \quad \vdots \quad \ell_{\mathrm{P}}=45.0 \mathrm{mi}-\ell_{\mathrm{N}}=26.0 \mathrm{mi} \\
& \overbrace{X}^{\text {Newark }} \underbrace{\stackrel{19.0 \mathrm{mi}}{\rightleftarrows}}_{55 \mathrm{mph}} \mid \underbrace{\underbrace{26.0 \mathrm{mi}}_{2}}_{75 \mathrm{mph}} \overbrace{\mathrm{X}}^{\text {Phil }}
\end{aligned}
$$

Figure 2. Solution to Problem B

While the solution in Figure 2, is the rigorous solution to Problem B, it presents at least three major hurdles for novice learners; 1 ) the mathematical steps for obtaining the answer may not be clear to the novice learner, 2) the novice learner may not understand and be able to identify the role of the steps in the solution and 3) as a result of 1 and 2 above, the novice learner will probably not be able to repeat the solution method for a similar STEM problem, i.e., transfer of knowledge fails. These three shortcomings are rectified by the SLEU method. An SLEU solution provides a systematic, universal problem solving scheme that students can practice and learn how to problem solve on their own. 
An SLEU solution for Problem B is shown in the tables below to demonstrate how to use the SLEU method to solve the problem. The SLEU solution will be shown as pairs of slides for each SLEU step. The slide on the left (lhs) will be a question that represents an SLEU step the student must perform. The right hand slide (rhs) will be the answer slide. Each pair of slides will represent a step in the SLEU solution.

Students will view the lhs slide and formulate their answer then move to the rhs to check to see if their answer is correct. In an SLEU Module, each pair of slides would be uploaded sequentially into a software program such as PowerPoint ${ }^{\mathrm{TM}}$ for distribution to students for individual, self-guided study.

STEP I - UNPACKING (NUMBERS, UNITS)

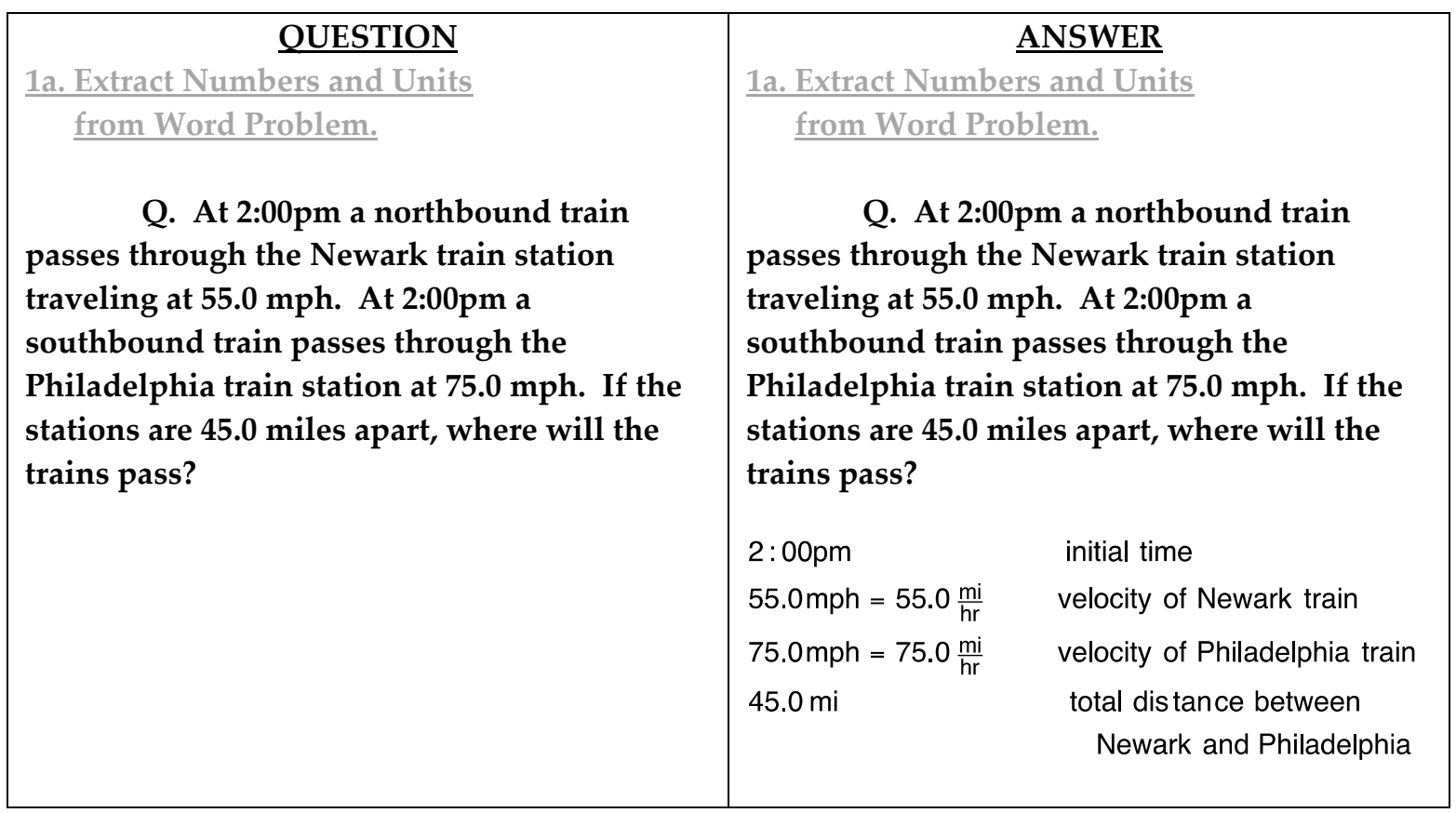

STEP II - UNPACKING (SYMBOLS WITH SUBSCRIPTS)

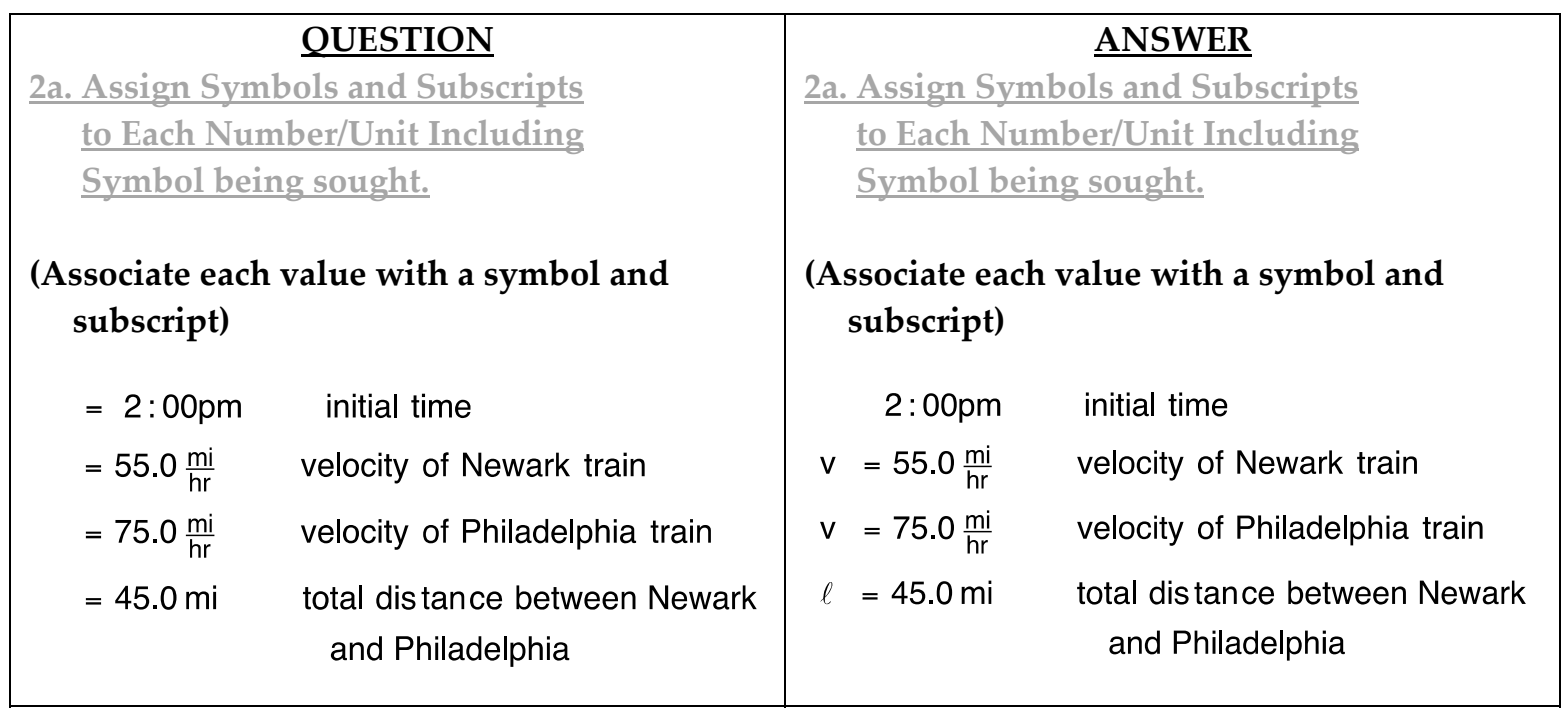




\begin{tabular}{|c|c|c|c|}
\hline \multirow{3}{*}{\multicolumn{2}{|c|}{$\begin{array}{l}\text { QUUSTION } \\
\text { 2a. Assign Symbols and Subscripts } \\
\text { to Each Number/Unit Including } \\
\text { Symbol being sought. } \\
\text { (Subscript each symbol.) } \\
\text { (NOTE: Two velocities so } \\
\text { subscripts definitely needed.) }\end{array}$}} & \multirow{3}{*}{\multicolumn{2}{|c|}{$\begin{array}{l}\text { ANSWER } \\
\text { 2a. Assign Symbols and Subscripts } \\
\text { to Each Number/Unit Including } \\
\text { Symbol being sought. } \\
\text { (Subscript each symbol.) } \\
\text { (NOTE: Two velocities so } \\
\text { subscripts definitely needed.) }\end{array}$}} \\
\hline & & & \\
\hline & & & \\
\hline $2: 00 \mathrm{pm}$ & initial time & $2: 00 \mathrm{pm}$ & initial time \\
\hline $\mathrm{v}=55.0 \frac{\mathrm{mi}}{\mathrm{hr}}$ & velocity of Newark train & $\mathrm{v}_{\mathrm{N}}=55.0 \frac{\mathrm{mi}}{\mathrm{hr}}$ & velocity of Newark train \\
\hline $\mathrm{v}=75.0 \frac{\mathrm{mi}}{\mathrm{hr}}$ & velocity of Philadelphia train & $\mathrm{v}_{\mathrm{P}}=75.0 \frac{\mathrm{mi}}{\mathrm{hr}}$ & velocity of Philadelphia train \\
\hline$\ell=45.0 \mathrm{mi}$ & $\begin{array}{l}\text { total dis tance between Newark } \\
\text { and Philadelphia }\end{array}$ & $\ell_{\mathrm{T}}=45.0 \mathrm{mi}$ & $\begin{array}{l}\text { total dis tance between Newark } \\
\text { and Philadelphia }\end{array}$ \\
\hline
\end{tabular}

STEP III - EQUATIONS AND SOLUTION

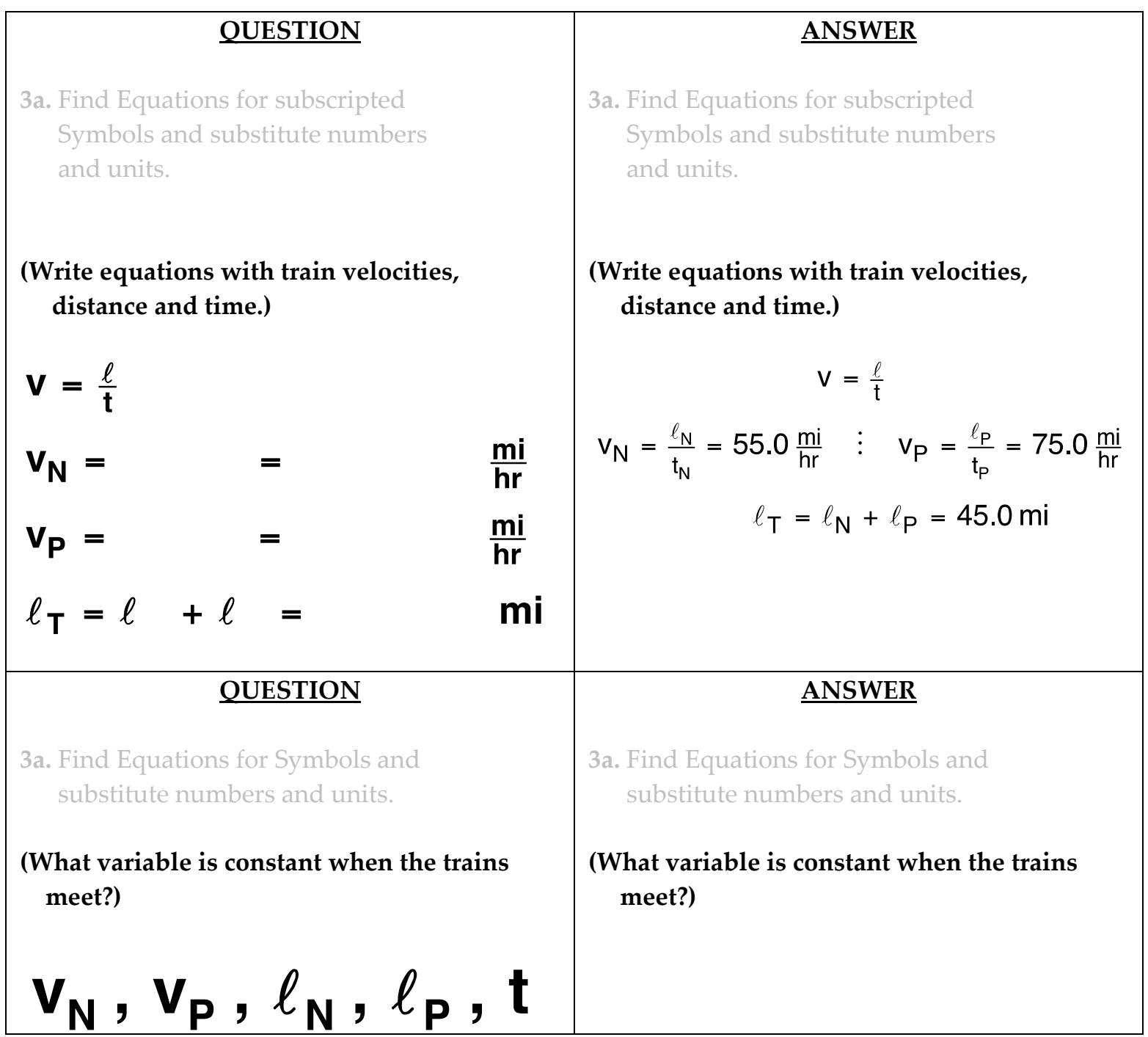


A. ??

\section{$v_{N}, v_{p}, \ell_{N}, \ell_{p}, \mathbf{t}$ \\ A: $\underline{\text { ime }}_{,} t=t_{N}=t_{p}$}

STEP III - EQUATIONS AND SOLUTION (continued)

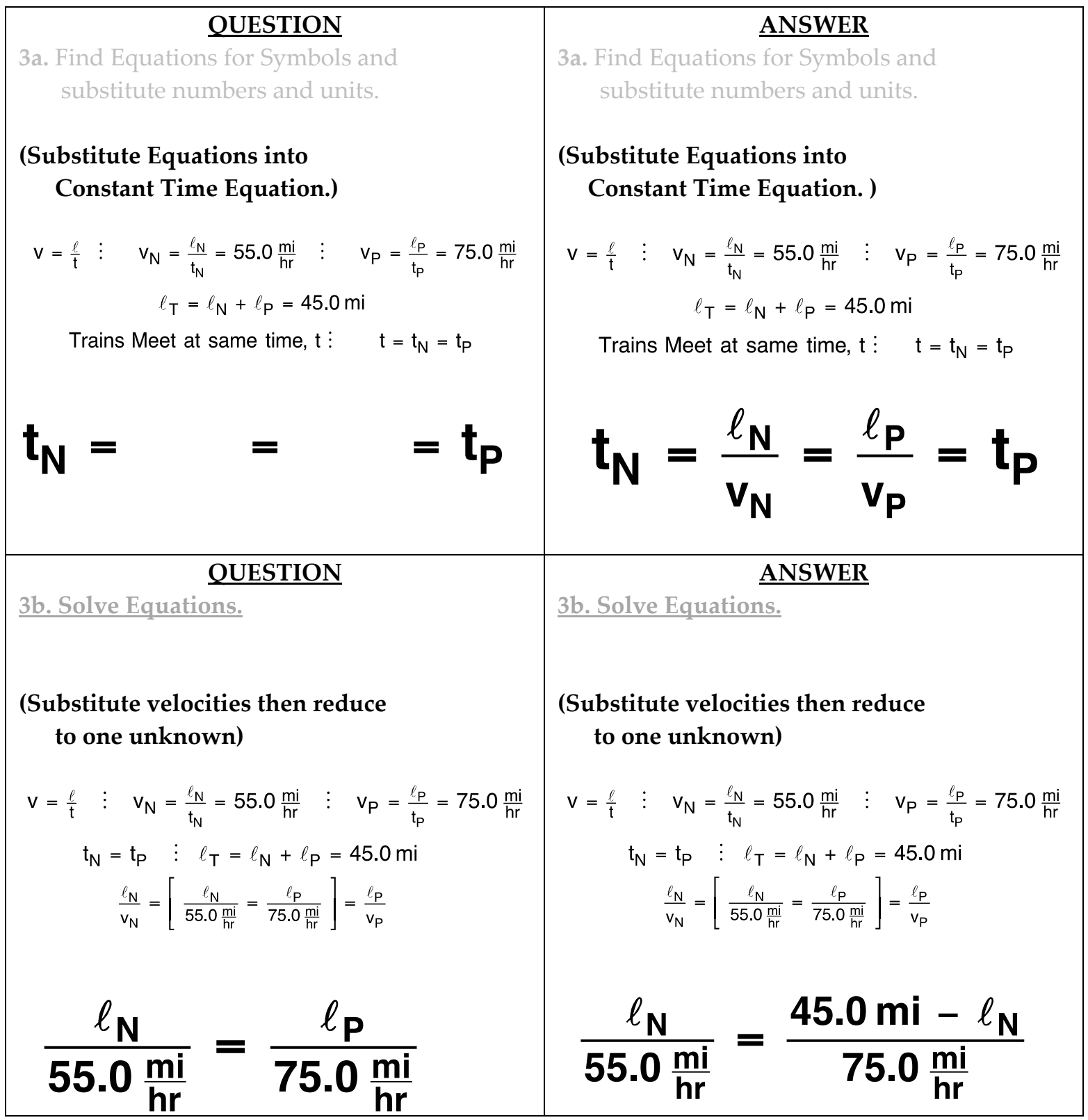

STEP III - EQUATIONS AND SOLUTION (continued)

\begin{tabular}{|l|l|}
\hline \multicolumn{1}{|c|}{ QUESTION } & \multicolumn{1}{c|}{$\underline{\text { ANSWER }}$} \\
3b. Solve Equations & $\underline{3 \mathrm{~b} . \text { Solve Equations }}$ \\
(Solve for Distances for Each Train.) & (Solve for Distances for Each Train.) \\
\hline
\end{tabular}




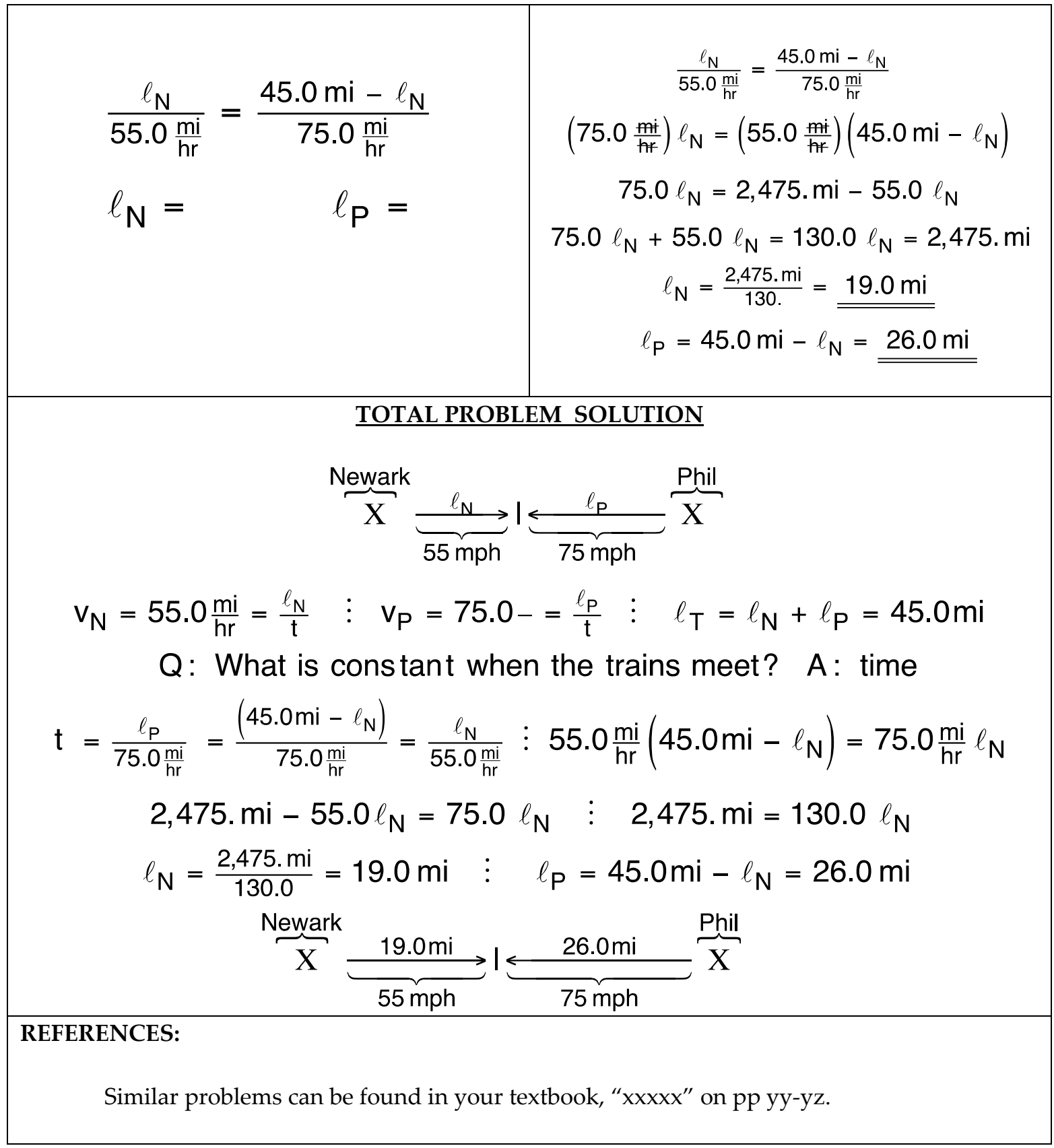

The tables above show the steps in the SLEU solution for Problem B. When each cell of the tables are uploaded sequentially into a computer format such as PowerPoint ${ }^{\mathrm{TM}}$, the computer program becomes an SLEU Module. The steps in the SLEU Module give students the opportunity to repeatedly review and practice the SLEU method for solving this and other STEM problems. Problem B in PowerPoint ${ }^{\mathrm{TM}}$ format can be found at the link:

https://drive.google.com/file/d/1pmvBkkMYhtJMVfbeyZZJWmNvtdTrFbww/view?usp=sharing

Step III in the SLEU process is the most difficult because it requires the student to find the equation or equations that contain the desired variable in terms of the subscripted variables identified with values, units and symbols in Step II. However, equation identification is made less difficult for STEM problems for topics students have heard in lecture, seen a textbook or seen in previously studied material. For step III students should be encouraged to "write down or look up all the equations" they know are related to this topic. This exercise serves to reinforce familiarity with equations and 
the physicochemical meaning of the variables in the equations. This random process of finding the desired equation by writing multiple related equations will become more directed and less random as students work more problems.

Another feature of the SLEU Modules is the fact that the "QUESTION" slides in an SLEU Module should be written to give students hints to help them proceed to the "ANSWER" slide. The "ANSWER" slide then is helpful in showing what the answer was for the weak student who may have to consult the answer slide. Alternatively, the strong student looks at the "ANSWER" slide to simply confirm that they understood what was being asked on the "QUESTION" slide. A well written SLEU Module serves as a valuable teaching and study tool for students at all ability levels. Moreover, if students have access to multiple SLEU Modules, the material and steps in the different SLEU Modules remains fresh and does not become memorized.

As pointed out by Zhang (2014), research has shown that cognition and metacognition play a key role in the SLEU problem solving process. A concept map of the cognitive and metacognitive steps in the SLEU process are given in Figure 3.

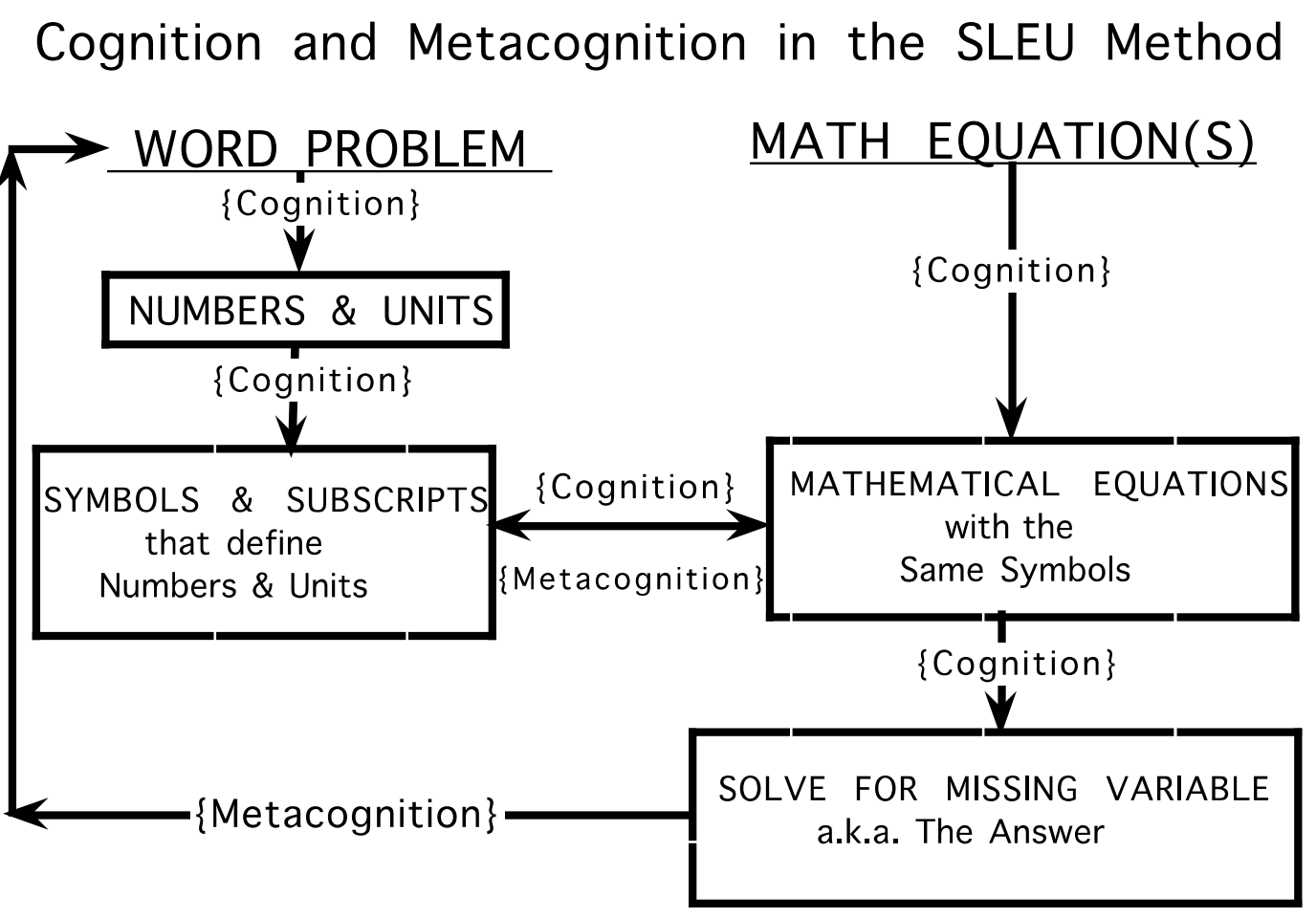

Figure 3. Cognition and Metacognition in the SLEU Process

Figure 3 shows the roles that cognition and metacognition play in the SLEU process. Pulling numbers and units out of a word problem and associating them with subscripted variables are clearly simple cognitive processes. Then finding the correct equation(s) is both cognitive and metacognitive. An equation is chosen based on the physicochemical principles of the problem (cognitive) then reviewed based on how the equation has been used in similar problems (metacognition).

Once the correct equation is selected it is solved mathematically which is a cognitive and final step. Finally, students should be trained to evaluate their answer with questions such as; 1) is the magnitude of my answer reasonable, 2) are the units reasonable, 3) describe what the answer means, etc.? Answering these questions is a metacognitive process. 
Additional information can be incorporated into SLEU Modules. A concept map of the SLEU method for writing SLEU Modules for STEM problems is shown in Figure 4. The process begins on the left with a "STEM Word Problem" and moves stepwise to the right to the "Final Math Solution". The map shows the SLEU steps. The map also shows other steps that can be included to enhance the teaching objectives of the instructor such as, "Add Physicochemical Principles". In addition, after the final math solution is reached, follow up slides can be added that encourage reflection on the problem, i.e., metacognition, can also be added.

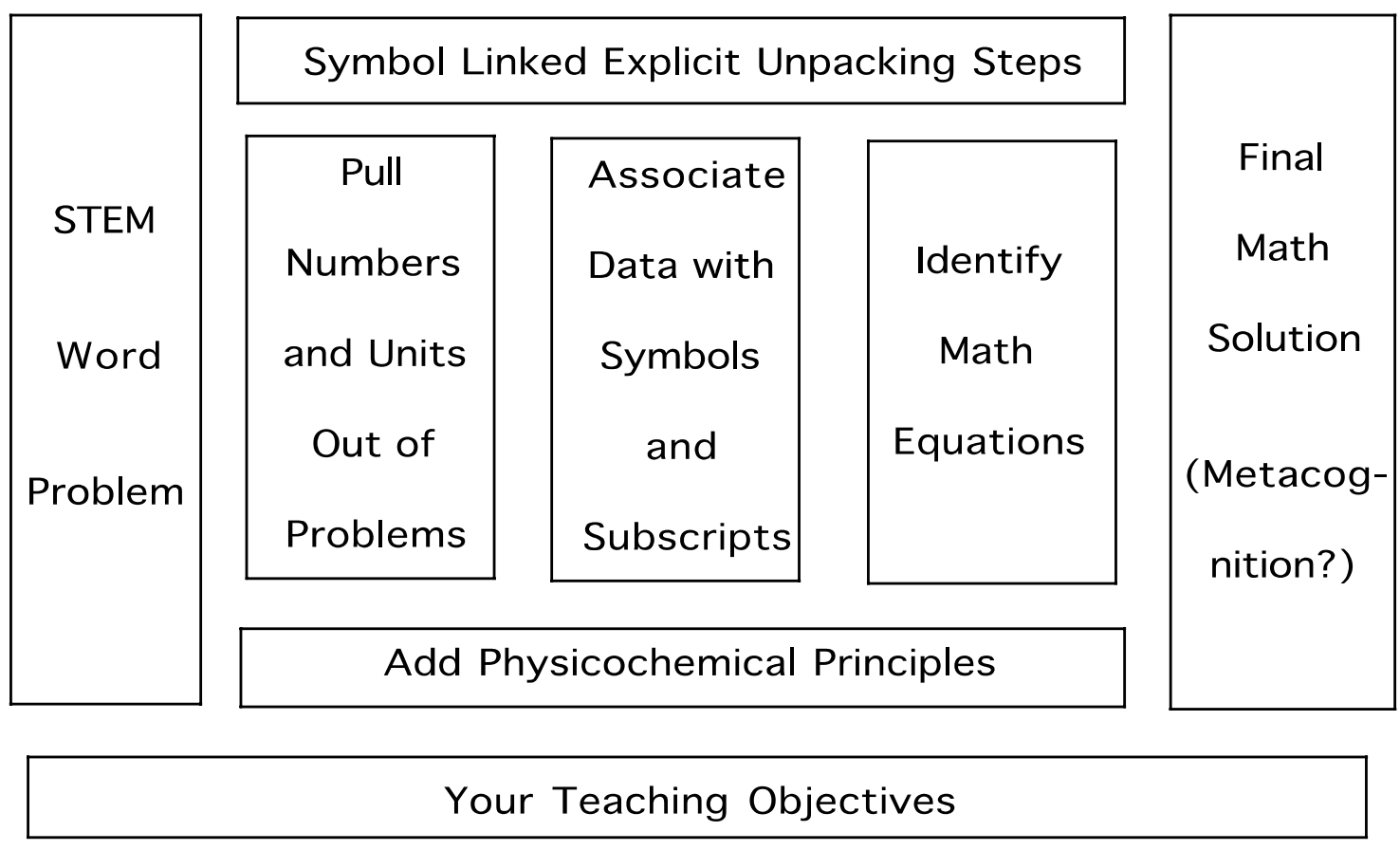

SLEU Method

Figure 4. Steps in the Explicit Unpacking Method

Some STEM problems include tables or diagrams necessary for problem solution. Examples include; 1) using an ICE table to solve acid-base problems, 2) identifying components in a Voltaic cell diagram in order to solve problems, 3) tabulated kinetic rate data tables. The data for these STEM problems may be given in the problem and/or a table. In either case a SLEU solution requires extracting the data from the problem (table or diagram) and assigning it a subscripted symbol. Step III can then be performed using the table or diagram as needed. Examples can be found at the following example websites.

ACID-BASE SLEU MODULE: For acid/base problems the ICE table is used between SLEU steps II and III. In steps I and II, the numbers and symbols are identified. Then the ICE table is uOLDsed with the data from SLEU steps I and II to incorporate the stoichiometry of the acid/base reaction. The data from the ICE table can then be used in the appropriate acid/base equations of STEP III of the SLEU process to solve the problem. An example of an SLEU module applied to an acid/base problem can be found at the following link.

https://drive.google.com/file/d/1h_LrCyJJoaN-loHAwbWhwewD7rF9Av5h/view?usp=sharing

VOLTAIC CELL SLEU MODULE: Step I still involves identifying the numbers and units from the problem but Step II involves associating the numbers and units with parts of a Voltaic cell, not with symbols and subscripts. Following the LOAN convention; Left, $\underline{\text { Oxidation, }}$ Anode, Negative, the 
parts of the Voltaic cell are identified and the numbers and units from Step I are then easily assigned. For Step III, the variable asked for in the question can be calculated. An example of an SLEU module applied to a Voltaic cell problem can be found at the following link.

https://drive.google.com/file/d/1XdZ2brgoYJHO3cyMGt538iC0kvXDz3Ls/view?usp=sharing

KINETIC RATE SLEU MODULE: Data for problems involving determination of the explicit kinetic rate equation are typically given in a table of experimental data. The experimental kinetic rate numbers, units, symbols and subscripts are Steps I and II of the SLEU process. For Step III the generic kinetic rate equation can always be written based on the number of reactants. For example, the generic rate equation for the reaction, $2 \mathrm{NO}_{(\mathrm{g})}+\mathrm{O}_{2(\mathrm{~g})}=2 \mathrm{NO}_{2(\mathrm{~g})}$, would be, $\mathrm{R}_{\mathrm{i}}=\mathrm{k}[\mathrm{NO}]_{\mathrm{i}}^{\mathrm{x}}\left[\mathrm{O}_{2}\right]_{\mathrm{i}}^{\mathrm{y}}$ The tabular data and the generic rate equation can then be used to calculate the reaction orders ( $\mathrm{a}$ and b) for the reactants and the kinetic rate constant, $\mathrm{k}$. An example of an SLEU module applied to a kinetic rate problem can be found at the following link.

https://drive.google.com/file/d/17RCbgu4_uBsgmctb5AVdkQKhMh0d5JPZ/view?usp=sharing

Student opinions of SLEU Modules were collected for a large class of second semester general chemistry students. Their opinions on the value of SLEU units is tabulated below.

\section{RESULTS}

About 20 SLEU Modules on various general chemistry II (second semester general chemistry) topics in Power Point ${ }^{\mathrm{TM}}$ format were made available to a class of 420 general chemistry II students in the spring semester of 2018. On a survey as part of the final exam the students were asked their opinion of the SLEU Modules with the Likert-format question, "The SLEU Modules helped improve my exam scores".

Out of the entire class, 380 students responded and the survey results are shown in Table 1.

TABLE 1. Student Survey Opinion Results for SLEU Module Question $\S$

\begin{tabular}{|c|c|}
\hline $\begin{array}{l}\text { Students } \\
\text { Responding }\end{array}$ & $\begin{array}{c}\text { Student } \\
\text { Response }\end{array}$ \\
\hline 223. & Agree or Strongly Agree \\
\hline 102. & Disagree or Strongly Disagree \\
\hline 65. & Did not use for exam study \\
\hline 380. & Total students responding \\
\hline
\end{tabular}

$\S$ Question: "The SLEU Modules helped improve my exam scores"

Student opinions of the 20 general chemistry II SLEU Modules are tabulated in TABLE 1. However, EU Modules were not available to any of these students during their general chemistry I course. Furthermore, these 420 students (of which 380 responded) had been instructed by 9 different general chemistry I instructors but they all had instructor 1 for general chemistry II. To determine if student opinions were dependent on their general chemistry I professor, the data in Table 2 were tabulated. 
TABLE 2. Student Survey Opinion Results for SLEU Module Question

\begin{tabular}{|c|c|c|}
\hline \multicolumn{2}{|c|}{$\underline{\text { Students Responding }}$} & Student Response \\
\hline Prof. $1^{*}$ & $\underline{8 \text { Other Profs }}{ }^{* *}$ & \\
\hline 118. & 105. & Agree or Strongly Agree \\
\hline 48. & 54. & Disagree or Strongly Disagree \\
\hline 40. & 15. & Did not use for exam study \\
\hline 206. & 174. & \\
\hline & & Total students responding \\
\hline
\end{tabular}

From the data in TABLE 2, student's opinions of the SLEU Modules do not show a significant dependence on their general chemistry I professor.

\section{CONCLUSION}

The problem solving method, Symbol Linked Explicit Unpacking (SLEU) was introduced. It was shown how STEM problems could be solved using this method and turned into SLEU Modules that could be uploaded to a computer software program for students to practice problem solving skills. Twenty SLEU modules were made available to 420 second semester general chemistry students. Of the 380 respondents, 223 students felt the SLEU Modules helped them improve their exam scores, 102 felt the SLEU modules did not help and 65 students did not use the SLEU Modules.

The data show that students found the SLEU Modules helped them perform better on exams. This fact is made more relevant by the fact that students were not required to use or even view the SLEU Modules. The SLEU Modules were made available but not assigned and did not represent any required component of the student's final course grade.

Since this was the second semester of a two semester general chemistry course, all 420 students had one of 9 possible professors for the first semester of general chemistry. To see if student opinions of the SLEU Modules would change based on the student's first semester general chemistry professor the data were re-sorted. The responses of students who felt the SLEU Modules improved test performance were 118/105 for students with the same professor for both semesters of general chemistry compared to those students with different professors. For students who did not find the SLEU Modules helpful the responses were 48/54 for students with the same vs. different general chemistry I professors. Reponses for students who did not use the SLEU Modules the responses were 40/15, respectively. 


\section{Acknowledgements}

Part of this research was presented at the Lilly Conference in Bethesda, MD held May 31-June 3, 2018. The authors would like to acknowledge the contributions of Briyana Chisholm in writing study exercises.

\section{References}

Adams, W. K. (2012). Problem solving assessment. The Journal of the Acoustical Society of America, $132(3), 1923$.

Ball, D. L. \& Bass, H. (2000). Interweaving content and pedagogy in teaching and learning to teach: Knowing and using mathematics. In J. Boaler (Ed.), Multiple perspectives on mathematics teaching and learning, 83-104. Westport, CT: Ablex Publishing.

Bauersfeld, H. (1995). The structuring of the structures: Development and function of mathematizing as a social practice. In L. P. Steffe, \& J. Gale (Eds.), Constructivism in education, 137-158. Hillsdale, NJ \& Hove, UK: Lawrence Erlbaum Associates Publishers.

Caine, G. Caine, R. N. \& Cromwell, S. (1994). Mindshifts: A brain-based process for restructuring schools and renewing education. Tuscon, AZ: Zephr Press.

Doll, W. C. (1989). Complexity in the classroom. Educational Leadership, 7(1). 6570.

Lesh, R., \& Doerr, H. M. (2003). Foundation of a models and modeling perspective on mathematics teaching, learning, and problem solving. In R. Lesh, \& H. M. Doerr (Eds.), Beyond constructivism: Models and modeling perspectives on mathematics problem solving, learning, and teaching, 3-34. Mahwah and London: Lawrence Erlbaum Associates Publishers.

Lester, F. K. (1994). Musings about mathematical problem-solving research: 1970-1994. Journal for Research in Mathematics Education, 25(6), 660-675.

Niss, M., Blum, W. \& Galbraith, P. (2007). Introduction. In Blum, W., Galbraith,P.L., Henn, H.-W. \& Niss, M. (Eds.), Modelling and Applications in Mathematics Education. The 14 th ICMI Study, 3-32. New-York: Springer.

Schoenfeld, A. H. (2007). Problem solving in the United States, 1970-2008: research and theory, practice and politics. ZDM Mathematics Education, 39, 537-551.

Shulman, L. S., \& Keislar, E. R. (1966). Learning by discovery. Chicago: Rand McNally.

Zhang, Pingping (2014), Unpacking Mathematical Problem Solving through a Concept-Cognition-Metacognition Theoretical Lens, Dissertation, Ohio State University.

Zhang, P., Brosnan, P., Erchick, D., \& Liu, Y. (2010). Analysis and inference to students' approaches about development of problem-solving ability. In P. Brosnan, D. Erchick, L. Flevares (Eds), Proceedings of the $32^{\text {nd }}$ annual conference of the Psychology of Mathematics Education North American Chapter. 